\title{
Teorías de la internacionalización de empresas
}

\author{
Theories of the internationalization of firms
}

\author{
Mariano José Merubia \\ Universidad Nacional de Jujuy, Argentina \\ mmerubia@face.unju.edu.ar
}

\section{Resumen}

Históricamente, el proceso de internacionalización ha sido identificado con dos modelos principales: el modelo sueco Upsala, desarrollado por Johanson y Wiedersheim-Paul (1975) y Johanson y Vahlne (1977), y el modelo americano de innovación, que deriva principalmente del trabajo de Andersen (1993); a ambos modelos Ruzzier los considera como modelos tradicionales de internacionalización (Ruzzier, Hisrich y Antoncic, 2006). Vahlne y Johanson, en su trabajo del año 2017, denominaron a la teoría de la internalización (Buckley y Casson, 1976; Rugman, 1981; Narula y Verbeke, 2015) y al paradigma ecléctico (Dunning, 1988, 1991) como perspectivas teóricas dominantes de la evolución multinacional. Dentro de los modelos no tradicionales de internacionalización, según el mismo autor (Ruzzier et al., 2006), se encuentran el enfoque de red (Coviello y Munro, 1997) y el enfoque de emprendimiento internacional (McDougall y Oviatt, 1997, 2000; Antoncic y Hisrich, 2001; Ruzzier et al., 2006). Se requiere el desarrollo de nuevas teorías de internacionalización, que incorporen el análisis de la dimensión de tiempo, el rol del emprendedor y el avance tecnológico en el proceso de internacionalización.

\section{Palabras clave}

Internacionalización - teorías - modelos tradicionales - modelos no tradicionales

\section{Abstract}

Historically, the internationalization process has been identified with two principal models: the Swedish's Upsala model developed by Johanson and Wiedersheim-Paul (1975) and Johanson and Vahlne (1977), and the American's Innovation model, that derives mainly from Andersen's work (1993); Ruzzier considers both models to be traditional models of internationalization (Ruzzier, Hisrich y Antoncic, 2006). Vahlne and Johanson in their 
2017 paper called the internalization's theory (Buckley y Casson, 1976; Rugman, 1981; Narula y Verbeke, 2015) and the eclectic paradigm (Dunning, 1988, 1991) as dominant theoretical perspectives on multinational evolution. Within the non-traditional models of internationalization according to the same author (Ruzzier et al., 2006) are the network approach (Coviello y Munro, 1997) and the international entrepreneurship approach (McDougall y Oviatt, 1997, 2000; Antoncic y Hisrich, 2001; Ruzzier et al., 2006). The development of new theories of internationalization is required; these should incorporate the analysis of the time dimension, the role of the entrepreneur, and technological change in the internationalization process.

\section{Keywords}

Keywords Internationalization - theories - traditional models - non-traditional models

\section{Introducción}

El modelo Upsala se focaliza en la adquisición, integración y uso del conocimiento acerca de los mercados extranjeros, así como también en un creciente compromiso y asignación de recursos a los mercados. El proceso es descrito como evolutivo, dinámico y cíclico. Deacuerdo con Johanson y Vahlne (1990), los dos patrones principales del proceso son el tipo de compromiso y la distancia psíquica.

En el modelo relacionado con la innovación, la internacionalización es considerada como una innovación en la empresa (Andersen, 1993). El modelo distingue una serie de etapas de internacionalización que se organizan en forma secuencial y fija.

La teoría de la internalización explica la existencia y funcionamiento de la empresa multinacional (Rugman, 1981) y contribuyea entender los límites de la misma, su interfaz con el entorno externo y su diseño organizativo interno.

El paradigma ecléctico identifica y evalúa la importancia de los factores que influencian el inicio de la producción internacional por parte de las empresas y el crecimiento de dicha producción; postulado inicialmente por Dunning (1977), es también conocido como el paradigma OLI por sus siglas en inglés ( $\mathrm{O}=$ ownership/propiedad]; $\mathrm{L}=$ localization/localización; I = internalization/ internalización).

El enfoquede redes considera las redes intraorganizacionales e interorganizacionales. Sus principales expositores son Covielloy Munro (1997), quienes señalan que las pequeñas y medianas empresas muestran un patrón de externalización de sus actividades durante los procesos de internacionalización, dependiendo en gran medida del establecimiento de redes. La perspectiva de red muestra que las actividades de desarrollo del mercado internacional surgen de, y están conformadas por, una red externa de relaciones formales e informales (Coviello y Munro, 1997). Jones, Covielloy Tang (2011) sostienen que las redes son cada vez más sofisticadas, que los vínculos de red son algo más que solo fuertes o débiles.

El enfoque del emprendimiento internacional es una nueva área de investigación entre la interfaz de la investigación de emprendimiento y los negocios 
internacionales (McDougall y Oviatt, 1997, 2000; Antoncic y Hisrich, 2001; Ruzzier et al., 2006). En contraste con las teorías tradicionales de internacionalización, este enfoque se centra más en la rápida internacionalización de las empresas (Bose, 2016). El concepto de emprendimiento internacional encuentra sus orígenes cuando los avances tecnológicos permitieron a las nuevas empresas acceder a los mercados extranjeros sin explotar.

El artículo se organiza de la siguiente manera. La segunda sección resume las distintas definiciones de internacionalización encontradas en la revisión de la literatura. En la tercera sección se describen las principales teorías de internacionalización tradicionales, las perspectivas teóricas dominantes de la evolución multinacional y las teorías no tradicionales. La última sección finaliza con las conclusiones y el planteamiento de nuevas líneas de investigación.

\section{Definiciones de internacionalización}

En la tabla 1, se muestran las distintas definiciones de internacionalización sobre la base de la revisión de la literatura realizada.

De todas las definiciones expuestas, la visión que adoptamos es la desarrollada por Petri Ahokangas (1998), quien define la internacionalización como «el proceso de movilización, acumulación y desarrollo de reservas de recursos para actividades internacionales».

Esta definición está inspirada en la teoría de recursos y capacidades (Barney, 1991), la cual destaca la importancia de los recursos a la hora de desarrollar las actividades internacionales.

\section{Teorías de internacionalización de empresas}

Este apartado, en primer lugar, desarrolla el modelo Upsala de internacionalización (Johanson y Vahlne, 1977; Johanson y Wiedersheim-Paul, 1975) y continúa con el modelo de innovación (Anderson, 1993; Bilkey y Tesar, 1977; Cavusgil, 1980; Czinkota, 1982; Reid, 1981). Ambos modelos son conocidos como tradicionales (Ruzzier et al., 2006), modelos de etapas (Bose, 2016; Chetty y Campbell-Hunt, 2004) o modelos de procesos. Luego se presentan las críticas a los modelos tradicionales de internacionalización.

Luego se analizan la teoría de la internalización (Buckley y Casson, 1976; Rugman, 1981; Narula y Verbeke, 2015) y el paradigma ecléctico (Dunning, 1988, 1991), denominados por Johanson y Vahlne (2017) como perspectivas teóricas dominantes de la evolución multinacional, finalizando con el análisis de las diferencias entre ambas perspectivas.

Después nos adentramos en el desarrollo del enfoque de red llevado a cabo por Coviello y Munro (1997) y el enfoque de emprendimiento internacional, cuyos principales expositores son McDougall y Oviatt (1997, 2000), Antoncic y Hisrich (2001) y Ruzzier et al. (2006).

\section{Modelo Upsala}

El primer modelo Upsala fue desarrollado por Johanson y Wiedersheim-Paul (1975) y Johanson y Vahlne (1977). Tiene su base 
Tabla 1

Definiciones de internacionalización

\begin{tabular}{|c|c|}
\hline Autor & Definición \\
\hline Johanson y Vahlne (1990) & $\begin{array}{l}\text { Es un proceso acumulativo en el que las relaciones se establecen, } \\
\text { desarrollan, mantienen y disuelven continuamente para alcanzar los } \\
\text { objetivos de la empresa. }\end{array}$ \\
\hline Beamish (1990) & $\begin{array}{l}\text { Proceso mediante el cual las empresas aumentan su conocimiento de las } \\
\text { influencias directas e indirectas de las transacciones internacionales en su } \\
\text { futuro, y establecen y llevan a cabo transacciones con otros países. }\end{array}$ \\
\hline Welch y Luostarinen (1993) & $\begin{array}{l}\text { Es el movimiento hacia el exterior de las operaciones internacionales de } \\
\text { una empresa. }\end{array}$ \\
\hline Johanson y Mattsson (1993) & $\begin{array}{l}\text { Es el proceso de adaptar las operaciones de la empresa (estrategia, } \\
\text { estructura, recursos, etc.) a los entornos internacionales. }\end{array}$ \\
\hline Calof y Beamish (1995) & $\begin{array}{l}\text { Es el proceso de incrementar la participación en las operaciones } \\
\text { internacionales. }\end{array}$ \\
\hline Ahokangas (1998) & $\begin{array}{l}\text { Es el proceso de movilización, acumulación y desarrollo de reservas de } \\
\text { recursos para actividades internacionales. }\end{array}$ \\
\hline Lehtinen y Penttinen (1999) & $\begin{array}{l}\text { Concierne las relaciones entre la empresa y su entorno internacional, } \\
\text { deriva su origen del proceso de desarrollo y utilización de la disposición } \\
\text { cognitiva y actitudinal del personal y se manifiesta concretamente } \\
\text { en el proceso de desarrollo y utilización de diferentes actividades } \\
\text { internacionales, principalmente operaciones internas, externas y } \\
\text { cooperativas. }\end{array}$ \\
\hline Young, Bell, y Crick (200o) & $\begin{array}{l}\text { Proceso de desarrollo de aumento de la participación en negocios } \\
\text { internacionales por la empresa. }\end{array}$ \\
\hline $\begin{array}{l}\text { Hitt, Ireland, y Hoskisson, } \\
(2007: 251)\end{array}$ & $\begin{array}{l}\text { Estrategia a través de la cual una empresa expande las ventas de sus bienes } \\
\text { y servicios a través de las fronteras de las regiones y países del mundo en } \\
\text { diferentes ubicaciones geográficas o mercados. }\end{array}$ \\
\hline Bose, T. K. (2016) & $\begin{array}{l}\text { Proceso de ir más allá que las operaciones locales y operar } \\
\text { internacionalmente. }\end{array}$ \\
\hline Bose, T. K. (2016) & $\begin{array}{l}\text { Es el proceso de adquisición, integración y utilización del conocimiento } \\
\text { y la experiencia en las operaciones internacionales con una participación } \\
\text { incremental en los mercados internacionales. }\end{array}$ \\
\hline
\end{tabular}

Fuente: Elaboración propia.

teórica en la teoría del comportamiento de la empresa; es un modelo tradicional de internacionalización. Este modelo enfatiza el aprendizaje organizativo como el motor del proceso de internacionalización de las empresas, el cual consiste en pequeños pasos por los cuales las empresas incrementan gradualmente su participación internacional (Johanson y Vahlne, 1977; Johanson y WiedersheimPaul, 1975).

Johanson y Wiedersheim-Paul (1975) delinearon cuatro etapas del crecimiento gradual de la participación extranjera que siguen las empresas en su camino a convertirse en totalmente internacionalizadas, donde las etapas 
sucesivas representan grados más altos de participación internacional (Anderson, 1993):

Etapa 1: Actividades de exportación no regulares.

Etapa 2: Exportación por medio de un representante independiente (agentes).

Etapa 3: Establecimiento de una filial deventa en el extranjero.

Etapa 4: Producción/fabricación extranjera.

La secuencia de las etapas están restringidas a un mercado de un país específico. Las cuatro etapas significan sucesivamente mayores compromisos de recursos y también conducen a experiencias de mercado e información bastante diferentes para la empresa. La primera significa que la empresa no hizo compromisos de recursos para el mercado y que carece de cualquier canal de información regular hacia y desde el mercado. La segunda significa que la empresa tiene un canal hacia el mercado, por medio del cual recibe información bastante regular acerca de los factores que influyen en las ventas; esto también significa un cierto compromiso con el mercado. La tercera significa un canal de información controlado en el mercado, dando a la empresa la habilidad de dirigir el tipo y cantidad de flujo de información del mercado a la empresa; durante esta etapa, la empresa también obtiene experiencia directa de los factores que influyen en los recursos. La cuarta etapa significa un compromiso de recursos aún mayor (Johanson y Wiedersheim-Paul, 1975).
A esta secuencia de etapas se la denominó cadena de establecimiento. No se espera que el desarrollo siempre siga toda la cadena: primero, porque varios mercados no son lo suficientemente grandes para las etapas en donde se exige mayor cantidad de recursos; y segundo, porque se esperan saltos en la cadena de establecimiento en empresas con extensiva experiencia en otros mercados (Johanson y Wiedersheim-Paul, 1975).

De acuerdo con el modelo Upsala, la creciente internacionalización puede atribuirse a que las empresas acumulan conocimientos sobre mercados específicos. Estos conocimientos son un recurso crítico, ya que los mismos son necesarios para operar en el extranjero y no se pueden adquirir fácilmente. Un segundo aspecto implica la asunción de que las empresas se trasladan a países distantes solo después de haber establecido una presencia en países más próximos. El modelo asume que las empresas primero se dirigen a los mercados que entienden mejor, luego irán entrando en países con una distancia psíquica cada vez mayor. Es probable que las empresas con una experiencia internacional extensiva perciban menos la distancia psíquica al nuevo país que aquellas con poca experiencia internacional. La distancia psíquica se define en términos de factores que impiden o perturban el flujo de información entre la empresa y las naciones objetivo; incluye factores lingüísticos, institucionales, culturales, educacionales, industriales, prácticas de negocios y políticos (Benito y Gripsrud, 1992; Johanson y Wiedersheim-Paul, 1975; Johanson y Vahlne, 1977).

El modelo Upsala puede ser útil a la empresa en la planificación y toma 
de decisiones respecto a las operaciones internacionales. El modelo indica cómo se relaciona con otras variables de internacionalización, lo que brinda una mejor base para planificar y ejecutar el proceso de internacionalización (Johanson y Vahlne, 1977).

Para explicar el carácter incremental de la internacionalización, Johanson y Vahlne (1977) han formulado un modelo dinámico, que distingue entre los aspectos estáticos y los aspectos de cambio. Los estáticos son el compromiso de mercado y el conocimiento acerca de los mercados y operaciones extranjeras; los de cambio, las decisiones para comprometer recursos y las actividades de negocios actuales. Los aspectos de cambio, a su vez, incrementan el conocimiento de mercado y estimulan un mayor compromiso de recursos en los mercados extranjeros en los ciclos subsecuentes (Andersen, 1993). Las variables de cambio son las variables cruciales (Johanson y Vahlne, 2017).

Este modelo no explica cómo inicia el proceso de internacionalización o la naturaleza del mecanismo por el cual el conocimiento afecta el compromiso (Andersen, 1993); solo explica cómo el compromiso internacional aumenta de acuerdo con el aprendizaje experiencial de las empresas (Almodóvar y Rugman, 2014).

Debido a los cambios en el entorno internacional del modelo original Upsala, este fue revisado en el año 2009 y se introdujo una visión de red de negocios. La asunción básica es que todas las empresas están conectadas en una red de relaciones con los clientes y proveedores, desde la cual acumulan conocimiento, confianza y, eventualmente, compromiso (Johanson y Vahlne, 2009).

El modelo Upsala revisado trata de abordar este problema con el argumento de la experiencia previa del emprendedor fundador. En este caso, se espera que el equipo directivo no solo tenga el conocimiento sino también que acceda a la red (Almodóvar y Rugman, 2014).

La característica más distintiva del modelo Upsala revisado es el enfoque en procesos: los procesos de desarrollo de conocimiento y compromiso de recursos. Este enfoque es más consistente con la teoría de recursos y capacidades de la empresa (Barney, 1991).

Aunque el modelo Upsala se extendióa través de sus distintas actualizaciones, la estructura y el contenido general se mantiene igual que el original desarrollado en el año 1977.

\section{Modelo de innovación}

El segundo mayor modeloquedescribela internacionalización de la empresa es el modelo de innovación. Considerado un modelo tradicional, sugiere que la internacionalización resulta de una serie de innovaciones degestión quese dan dentro de la empresa. El modelo distingue una serie de etapas de internacionalización, organizadas como un desarrollo secuencial y fijo del proceso de internacionalización (Andersen, 1993; Bilkeyy Tesar, 1977; Cavusgil, 1980; Czinkota, 1982; Reid, 1981); este modelo busca especialmente clasificar el desarrollo en etapas, en lugar de explicar cómo las empresas se mueven de una etapa a otra.

Los modelos de etapas relacionados con la innovación se presentan en la tabla 2. 
Tabla 2

Modelos de etapas relacionados con la innovación

\begin{tabular}{|c|c|c|c|}
\hline Bilkey y Tesar (1977) & Cavusgil (1980) & Czinkota (1982) & Reid (1981) \\
\hline $\begin{array}{l}\text { E1: Los directivos no } \\
\text { están interesados en } \\
\text { exportar }\end{array}$ & $\begin{array}{l}\text { E1: Comercialización } \\
\text { local: la empresa solo } \\
\text { vende en el mercado } \\
\text { local }\end{array}$ & $\begin{array}{l}\text { E1: Empresa } \\
\text { completamente } \\
\text { desinteresada }\end{array}$ & $\begin{array}{l}\text { E1: Conciencia de } \\
\text { exportación: problema } \\
\text { de reconocimiento de } \\
\text { oportunidad, despertar } \\
\text { la necesidad }\end{array}$ \\
\hline $\begin{array}{l}\text { E2: Los directivos } \\
\text { completarían una } \\
\text { orden de exportación } \\
\text { no solicitada, pero no } \\
\text { harían el esfuerzo de } \\
\text { explorar la factibilidad de } \\
\text { exportación }\end{array}$ & $\begin{array}{l}\text { E2: Etapa de pre- } \\
\text { exportación: la } \\
\text { empresa busca } \\
\text { información y } \\
\text { evalúa la factibilidad } \\
\text { de emprender } \\
\text { exportaciones }\end{array}$ & $\begin{array}{l}\text { E2: Empresa } \\
\text { parcialmente interesada }\end{array}$ & $\begin{array}{l}\text { E2: Intención de } \\
\text { exportar: motivación, } \\
\text { actitud, creencias y } \\
\text { expectativas acerca la } \\
\text { exportación }\end{array}$ \\
\hline $\begin{array}{l}\text { E3: Los directivos } \\
\text { exploran activamente } \\
\text { la factibilidad de } \\
\text { exportación }\end{array}$ & $\begin{array}{l}\text { E3: Participación } \\
\text { experimental: la } \\
\text { empresa comienza } \\
\text { a exportar sobre } \\
\text { una base limitada a } \\
\text { algunos países cercano } \\
\text { psicológicamente }\end{array}$ & E3: Empresa exploradora & $\begin{array}{l}\text { E3: Prueba de } \\
\text { exportación: experiencia } \\
\text { personal de exportación } \\
\text { limitada }\end{array}$ \\
\hline $\begin{array}{l}\text { E4: Las empresas } \\
\text { exportan de manera } \\
\text { experimental con algún } \\
\text { país psicológicamente } \\
\text { cercano }\end{array}$ & $\begin{array}{l}\text { E4: Participación } \\
\text { activa: exportación a } \\
\text { más nuevos países - } \\
\text { exportación directa } \\
\text { - aumento en el } \\
\text { volumen de ventas }\end{array}$ & $\begin{array}{l}\text { E4: Empresa } \\
\text { experimental }\end{array}$ & $\begin{array}{l}\text { E4: Evaluación de la } \\
\text { exportación: resultados } \\
\text { de participar en la } \\
\text { exportación }\end{array}$ \\
\hline $\begin{array}{l}\text { E5: La empresa } \\
\text { es un exportador } \\
\text { experimentado }\end{array}$ & $\begin{array}{l}\text { E5: Participación } \\
\text { comprometida: } \\
\text { Los directivos } \\
\text { constantemente } \\
\text { hacen elecciones en } \\
\text { la disposición de los } \\
\text { recursos limitados } \\
\text { entre los mercados } \\
\text { locales y extranjeros }\end{array}$ & $\begin{array}{l}\text { E5: Pequeño exportador } \\
\text { experimentado }\end{array}$ & $\begin{array}{l}\text { E5: Aceptación de } \\
\text { exportación: adopción } \\
\text { de la exportación } \\
\text { o rechazo de la } \\
\text { exportación }\end{array}$ \\
\hline $\begin{array}{l}\text { E6: Los directivos } \\
\text { exploran la factibilidad } \\
\text { de exportar a países } \\
\text { adicionales que } \\
\text { psicológicamente están } \\
\text { más alejados }\end{array}$ & & $\begin{array}{l}\text { E6: Gran exportador } \\
\text { experimentado }\end{array}$ & \\
\hline
\end{tabular}

Fuente: Elaboración propia.

Los modelos presentados comparten muchas características. La principal diferencia está en el número de etapas y la descripción de cada etapa. A excepción del mecanismo de iniciación, las diferencias entre los modelos parecen reflejar 
diferencias semánticas más que diferencias reales acerca de la naturaleza del proceso de internacionalización (Andersen, 1993). En cada etapa, el grado de innovación es normalmente mayor en etapas posteriores en comparación con las anteriores.

El modelo desarrollado por Bilkey y Tesar (1977) destaca que la teoría del aprendizaje es aplicable al proceso de desarrollo de la exportación, sugiere que las empresas en sus etapas de exportación iniciales deberían centrarse en países psicológicamente cercanos y las empresas en etapas posteriores centrarse en países psicológicamente más distantes; establece que un país en desarrollo no debería imitar a ciegas programas de desarrollo de exportación que son apropiados para países industrializados. Se indica también que las empresas pequeñas y medianas pueden exportar exitosamente; la exportación no se limita para empresas grandes. Las contribuciones de Bilkey y Tesar sostienen que el tamaño de la empresa no es demasiado importante para el comportamiento exportador, cuando se toma en cuenta la calidad y el dinamismo de la gestión.

Ambos modelos, el Upsala y el de innovación, son considerados modelos tradicionales de internacionalización; ello implica que esta ocurre como una sucesión de etapas incrementales. Ambos están orientados al comportamiento y atribuyen la naturaleza lenta e incremental de la internacionalización a dos factores. (1) Falta de conocimiento de mercado de la empresa, en este caso es especialmente importante el conocimiento experiencial; Penrose (1959) distingue dos tipos de conocimiento: el objetivo, que puede ser enseñado, y el experiencial, que solo puede ser adquirido mediante la experiencia personal. (2) La incertidumbre asociada con decisiones sucesivas de internacionalizarse. Ambos modelos son útiles para clasificar las empresas de acuerdo con su grado de internacionalización, ninguno de los dos puede ser usado para explicar y predecir el paso de las empresas desde una etapa de desarrollo a otra (Andersen, 1993).

Tabla 3

Similitudes y diferencias entre el modelo Upsala y el modelo de innovación

\begin{tabular}{|l|l|c|}
\hline \multicolumn{1}{|c|}{ Modelo Upsala } & \multicolumn{1}{c|}{ Modelo de innovación } \\
\hline \multirow{5}{*}{ Similitudes } & * Conocidos como enfoques basados en etapas, procesos, tradicionales \\
\cline { 2 - 3 } & * Internacionalización como sucesión de etapas incrementales \\
\cline { 2 - 3 } & * Orientados al comportamiento \\
\hline \multirow{2}{*}{ Diferencias } & * Clasificación de la empresa de acuerdo con su grado de internacionalización \\
\cline { 2 - 3 } & * No explican el paso de una empresa desde una etapa de desarrollo a la otra \\
\hline \multirow{2}{*}{$\begin{array}{l}\text { Factores de } \\
\text { internacionalización }\end{array}$} & * Aprendizaje organizativo & \multirow{2}{*}{ * Innovaciones de gestión } \\
\cline { 2 - 3 } & * Distancia psíquica & \\
\hline
\end{tabular}

Fuente: Elaboración propia. 


\section{Críticas al modelo Upsala y de innovación}

Algunos autores sostienen que los modelos Upsala y de innovación son demasiado deterministas, de valor limitado (Reid, 1983) yomiten considerar que las empresas pueden no seguir un camino consistente para internacionalizarse (Knighty Cavusgil, 1996), que las empresas frecuentemente se saltan etapas (Oviatt y McDougal, 1994), que simplifican demasiado un proceso complejo y que ignoran el impacto de las variables exógenas.

El modelo Upsala asume que la internacionalización evoluciona sistemáticamente, casi sin cesar, desde una situación de no implicación, a la exportación y finalmente a la fabricación local. El modelo plantea que una vez que el proceso de internacionalización se ha iniciado, tenderá a continuar independientemente de si las decisiones estratégicas en esa dirección se toman o no (Johanson y Vahlne, 1990).

Sin embargo, es probable que muchas empresas se basen en una cuidadosa creación de estrategias, lo que representa una gama potencialmente amplia de condiciones de mercado de productos y de las opciones de la empresa. La decisión de pasar a ser internacional puede ser cuidadosamente planificada y basarse en la consideración de un número de factores como, por ejemplo, la naturaleza de la oportunidad del mercado extranjero, los recursos de la empresa, el tipo de producto, los ciclos de vida del producto y la demanda anticipada en el mercado local (Knight y Cavusgil, 1996).

Los modelos de procesos carecen de poder explicativo. No se trata adecuadamente por qué y cómo ocurren los procesos, o cómo predecir el movimiento de una etapa a la siguiente. Se pone poca atención a la dimensión tiempo del proceso, es demasiado general como para permitir la precisión. Esto está probablemente conectado al problema de la delimitación entre etapas (Andersen, 1993).

También se argumenta que el modelo Upsala es importante solo con relación a las primeras etapas de la internacionalización, cuando la falta de conocimiento del mercado y los recursos del mercado siguen siendo factores restrictivos. Cuando la empresa ya tiene actividades en muchos países, esos factores ya no son un problema (Johanson y Vahlne, 1990). Se sostiene que el modelo Upsala no toma en cuenta las interdependencias entre los diferentes mercados de los países.

Los modelos Upsala y de innovación parecen apoyarse sobre viejas asunciones, de los años sesenta, sobre el comportamiento de las empresas; en cambio, las teorías posteriores, como la teoría de la internalización y el paradigma ecléctico, incorporan la influencia del tamaño del mercado y consideran al tomador de decisiones como estratégicamente más consciente (Andersen, 1993). Este modelo de internacionalización reduce a la mínima expresión la influencia de factores individuales y contingentes (Plá y León, 2016).

En respuesta a las críticas al modelo, Johanson y Vahlne (1990) sugieren que hay tres excepciones a su modelo incremental de compromiso de mercado como una respuesta al aumento del conocimiento de mercado. Las excepciones son las siguientes: primero, se espera que las empresas con muchos recursos den grandes pasos 
hacia la internacionalización, ya que el proceso podría acortarse dado que las consecuencias de una inversión errónea son menores; segundo, cuando las condiciones del mercado extranjero son estables y homogéneas, el aprendizaje acerca de ellas es más fácil y puede adquirirse no solo a través de la experiencia; tercero, cuando las empresas tienen una considerable experiencia con mercados que sean similares a los nuevos objetivos de mercados extranjeros, la experiencia puede ser generalizable al nuevo escenario.

\section{Teoría de la internalización}

La teoría de la internalización fue conceptualizada por Buckley y Casson (1976) y Rugman (1981). Explica la existencia y funcionamiento de la empresa multinacional (Rugman, 1981) y contribuye a entender los límites de la misma, su interfaz con el entorno externo y su diseño organizativo interno. Las empresas multinacionales bajo una misma propiedad y control agrupan varias actividades interdependientes, desarrolladas en distintos países y unidas por flujos de productos intermedios (Buckley y Casson, 1976).

En las empresas actuales, además de la producción de bienes y servicios, se desarrolla una serie de actividades de gran importancia, actividades interdependientes conectadas por flujos de productos intermedios. En ocasiones, estos productos intermedios son simplemente materiales semiprocesados que pasan de una empresa a otra, pero en la mayoría de los casos se trata de determinado tipo de conocimiento y experiencia. Esta distinción permite clasificarlos en (a) productos intermedios tangibles, aquellos que conectan las distintas etapas de la cadena de producción, y (b) productos intermedios intangibles (conocimiento o know-how), referidos a la forma específica en que la empresa produce los bienes y servicios que aporta. A algunos países les resulta más difícil llevar a cabo estos productos intermedios, ya que sus sistemas de educación no son lo suficientemente buenos y la transferencia de tecnología se complejiza. El intercambio de productos intermedios puede tener lugar en el mercado o en el interior de la empresa. En ocasiones, el intercambio de productos intermedios en el mercado es difícil de organizar debido a las imperfecciones de este; por ello, la empresa intenta evitar estas transacciones coordinándolas en su interior, es decir, internalizando.

Uno de los conceptos clave de esta teoría se refiere a las ventajas específicas de la empresa (FSA, por sus siglas en inglés: firm specific advantage) desarrollado por Hymer (1976); la presencia de estas es un prerrequisito para la expansión internacional (Rugman y Verbeke, 2008). Las ventajas específicas de la empresa son las fortalezas de esta en relación con sus principales competidores, que permiten su supervivencia, rentabilidad y crecimiento (Verbeke, Amin Zargarzadeh, y Osiyevskyy, 2014). Cualquier elección de expansión internacional de una empresa - en términos de escala, modo de entrada o localización, o en términos de su tiempo- será condicionada por sus ventajas específicas, ya sean las existentes (permiten una explotación exitosa de las combinaciones de recursos existentes) o las futuras (requiriendo la exploración, en el sentido de la creación de nuevas combinaciones de recursos) (Verbeke et al., 2014). Ejemplos de ventajas específicas 
se refieren a la marca, las habilidades de gestión u organizativas, entre otras; están basadas en la eficiencia y son compatibles con la teoría de recursos y capacidades.

Buckley y Casson (1976) y Rugman (1981) son considerados los autores de la vieja teoría de la internalización, donde el foco se centra en los costes de transacción, en la eficiencia económica y el desarrollo, en el despliegue y explotación de las ventajas específicas de la empresa para superar las fallas naturales y no naturales de mercado.

Los costes de transacción vienen estimados por la valoración en términos monetarios de los consumos necesarios para la realización del intercambio; la manifestación y cuantía de los costes de transacción dependen de la naturaleza de la transacción y de la forma en que se organice la misma. La empresa tiende a minimizar estos costes para ser más eficiente. Los costes de transacción nos permiten entender las preferencias por diferentes grados de control asociados a los modos de internacionalizar la producción y el comercio (control total frente a control compartido). Los costes de transacción parten de que los mercados son competitivos (elevado número de participantes) y que las propias presiones de estos reducen la necesidad de vigilar el comportamiento de los productores. En estas condiciones es preferible utilizar el mercado frente a otras alternativas. En cambio, cuando se producen fallas de mercado es preferible internalizar las actividades o realizar alianzas como como alternativas eficientes.

Rugman y Verbeke (1992, 2003) son considerados los autores de la nueva teoría de la internalización, en donde hacen explícita la necesidad de modelar la organización interna de las empresas multinacionales y sus capacidades de red, además de centrarse en las ventajas específicas de la empresa, como las fortalezas en I+D, en la fabricación y en la creación de marca. La nueva teoría de la internalización de Rugman y Verbeke (2003) integra la perspectiva económica de los costes de transacción de la vieja teoría de internalización con la teoría de recursos y capacidades sobre la generación, transferencia y explotación de los recursos. La teoría de recursos y capacidades reinventó el concepto de las ventajas específicas de la empresa y las renombró como capacidades o competencias centrales.

Debido a la presencia de la falla de mercado, la internalización actúa para desarrollar y explotar las ventajas específicas de empresa. La internalización es una alternativa al mercado externo para desarrollar y explotar el conocimiento; en términos más generales, Buckley y Casson (1976) demostraron que cualquier tipo de imperfección de mercado puede hacer presión para internalizar las actividades de las empresas multinacionales.

La expansión internacional a través de subsidiarias de propiedad total tiene lugar dentro de la empresa multinacional cuando los beneficios de la internalización —en términos de desarrollo, despliegue, explotación y aumento de las ventajas específicas de empresa- pesan más que los costes de hacer negocios en el extranjero a niveles nacional y regional, y los beneficios netos resultantes son mayores que aquellos asociados con modos de entrada alternativos (exportación, licencias o alianzas estratégicas). Los beneficios de la internalización también se 
presentan como una alternativa de evitar las imperfecciones de mercado en el lugar donde se vaya a establecer la empresa (Buckley y Casson, 2009).

La versión de Rugman de la teoría de la internalización usa las grandes empresas multinacionales como su unidad básica de análisis, ya que estas representan el caso de gobierno más complejo -típicamente implica múltiples líneas de productos y múltiples mercados-, y puede implicar categorías de transacciones conducidas entre la empresa multinacional y una variedad de stakeholders del negocio y fuera del negocio, así como dentro de la empresa (Narula y Verbeke, 2015). Sin embargo, la teoría de la internalización puede ser fácilmente aplicable a nivel de transacciones simples y en configuraciones más sencillas como las empresas Born Global o las empresas locales, como lo argumentan en su trabajo Verbeke et al. (2014).

Buckley y Casson (2009) sostienen que la teoría de la internalización ha retenido su validez en los últimos años, y que actualmente se está extendiendo a nuevos campos de investigación de negocios internacionales. La extensión y el progreso de esta teoría se logran combinando este enfoque central con otros principios para generar una amplia gama de predicciones sobre diferentes aspectos del comportamiento organizativo. Esta puede ser combinada con la teoría del comercio para explicar la localización de las operaciones de la empresa, con la teoría de la organización para explicar las alianzas estratégicas internacionales, y con otras teorías de innovación para explicar los tipos de industria en las que puede operar una empresa.

En síntesis, las empresas multinacionales elegirán un mecanismo de gobierno comparativamente más eficiente en lugar de los menos eficientes, para llevar a cabo actividades económicas cuyo objetivo principal es desarrollar, desplegar, explotar y aumentar aún más las ventajas específicas de la empresa a través de las fronteras, es decir, que se elegirá aquella opción que minimice los costes de transacción. Las ventajas específicas de la empresa son la razón de ser para la presencia de estas empresas y determinan el alcance (niveles de diversificación de productos, integración vertical y diversificación geográfica) de las actividades económicas en las cuales la empresa se involucra.

La internacionalización de empresas (IDE) se produce cuando una empresa decide que es más conveniente instalarse físicamente en el exterior para produciry vender bienes y servicios. Es decir, la explotación de las ventajas específicas de la empresa más allá de sus fronteras, en lugar de venderlas a otras empresas extranjeras (del país de destino), constituye la esencia de la internalización. La alternativa a la IDE es la venta del activo a otras empresas o la concesión de una licencia, mediante la cual empresas en el exterior pueden utilizar, por un precio, los conocimientos de la empresa propietaria para fabricar y vender los productos en cuestión. La extensión de la organización a escala internacional mediante la IDE lleva asociados costes de vigilancia y control que, lógicamente, han de ser inferiores a los beneficios derivados de la internalización (reducción de costes de transacción) y a 
los costes de transacción asociados a otras alternativas.

\section{Paradigma ecléctico}

El concepto de paradigma ecléctico de la producción internacional fue presentado por primera vez por Dunning, en 1977. La intención fue ofrecer un marco holístico por el cual sea posible identificar y evaluar la importancia de los factores que influencian el inicio de la producción internacional por parte de las empresas y el crecimiento de dicha producción. Se acepta que, precisamente por su generalidad, el paradigma ecléctico tiene un poder limitado para explicar o predecir tipos particulares de producción internacional y, aún menos, el comportamiento de las empresas individuales.

Su principal contribución ha sido ensamblar, dentro de un sistema de aportaciones de los teóricos de la organización industrial - para quienes la posesión de una ventaja competitiva explicaba la aparición de la empresa multinacional—, el paradigma de los costes de transacción que buscaba en la internalización la razón de ser de las multinacionales, y las teorías de la localización y el comercio internacional donde se incidía en la importancia de las dotaciones de factores en determinadas localizaciones (Plá y León, 2016).

De acuerdo con Dunning, la decisión de la empresa de entrar a un mercado extranjero y la elección del modo de entrada depende de sus ventajas de propiedad $(\mathrm{P})$, ventajas de localización (L) y ventajas de internalización (I). Las decisiones de entrada en el mercado internacional son realizadas de una manera racional, basadas en un análisis de los costes de transacción, por lo que el enfoque del paradigma ecléctico y del coste de transacción contribuye a una explicación más completa de las operaciones en el extranjero.

Las ventajas de la propiedad (P) pueden ser divididas dentro de ventajas de activos (Pa) y variables transaccionales $(\mathrm{Pt})$. Las ventajas de activos incluyen varios activos tangibles e intangibles como las patentes tecnológicas, el nombre de la marca, estructura de la empresa, capacidad organizativa, equipo humano, know-how, etc.; mientras que las variables transaccionales $(\mathrm{Pt})$ se refieren a las fortalezas para coordinar una red de filiales geográficamente dispersas y tomar ventajas de su operación (Rugman, Verbeke y Nguyen, 2011), es decir, capturar los beneficios transaccionales o reducir los costes de transacción que surgen de la gobernanza común de una red de estos activos, localizados en diferentes países (Dunning, 1988).

La ventajas de la localización (L) reflejan a los países extranjeros que tienen alguna «ventaja específica país» con relación a otros países, en términos de los recursos naturales, factores de producción, condiciones de demanda, etc. Las ventajas de la localización incluyen elementos de la cultura, legales, políticos y un amplio entorno institucional en el que operan las empresas, y que hacen a algunos países más atractivos que otros, es decir, dotaciones específicas de factores no transferibles a lo largo de sus fronteras. Además, Dunning (1988) identifica la estructura de mercado a nivel país y políticas de gobierno como ventajas de localización potenciales (Rugman et al., 2011). Por medio de las ventajas de 
localización, una empresa busca factores de producción (recursos naturales, situación geográfica, factor trabajo, infraestructuras específicas), acceso a un mercado, economías de aglomeración e infraestructura adecuada (telecomunicaciones, aeropuertos, carreteras, puertos, etc.).

Las ventajas de la internalización (I) se refieren a los beneficios de la creación, transferencia, despliegue y recombinación, y explotación de las ventajas específicas de las empresas internamente, en lugar de realizar acuerdos contractuales con las partes externas. Los factores que conducen a la internalización de las ventajas propias son aquellos derivados de la reducción de los costes de transacción; entre otros, podemos señalar la necesidad del vendedor de proteger la calidad de los productos, el evitar los costes de búsqueda, negociación y ruptura de los contratos, el compensar la ausencia de mercados, evitar o explotar intervenciones gubernamentales, etc. Mediante la internalización se facilita la calidad de los productos así como la preservación (protección) de las ventajas tecnológicas y el uso de conocimientos tácitos de la empresa. Es la condición suficiente para evidenciar que la IDE es la mejor alternativa para rentabilizar las ventajas propias de la empresa. Finalmente, con relación a las ventajas de internalización, la utilización de las alianzas se ha revelado como una alternativa válida en el proceso de internacionalización de la empresa, pues en determinadas circunstancias permite alcanzar los mismos objetivos de forma más eficiente, al reducir el riesgo y el capital invertido.
El paradigma ecléctico sostiene que el significado de cada una de estas ventajas y la configuración entre ellas variará entre las industrias, regiones o países y entre las empresas, y entre los motivos que subyacen a la producción (Dunning, 1988).

La teoría de las empresas multinacionales tiende a enfatizar que la razón principal para la producción internacional es la existencia de fallas o imperfecciones transaccionales de mercado (Dunning, 1988). La segunda condición para la producción internacional es que a las empresas multinacionales que posean ventajas específicas de propiedad le deba convenir transferir las mismas a través de las fronteras nacionales dentro de su propia organización - dentro de una sola empresa-, en lugar de vender o ceder su derecho de uso a terceras empresas con sede en el extranjero.

Las fallas o imperfecciones de mercado pueden ser estructurales y transaccionales, y afectan tanto a las ventajas de propiedad (P), a las de localización (L) y a las de internalización (I). Entre las imperfecciones estructurales están las barreras de entrada, las barreras a la competencia, las de intervención del gobierno (tipo de política comercial diseñada y su actitud frente al capital exterior) y las fallas espaciales. Entre las imperfecciones transaccionales están las que surgen de la capacidad de las empresas para explotar las economías de producción a gran escala, la falta de información, las que surgen del riesgo y la incertidumbre y las de la gobernanza común, este tipo de fallas de mercado se evita o reduce a través de la planificación y coordinación en el seno de la empresa (Plá y León, 2016). 
Las diferencias entre fallas estructurales y transaccionales de mercado son importantes. La importancia de cada una en la determinación de las ventajas de propiedad de las empresas multinacionales variará de acuerdo con las características de cada empresa, los productos que produce y los mercados en los cuales opera. Las empresas multinacionales más exitosas son aquellas que pueden nutrir y explotar las dos, ambas están interrelacionadas, particularmente en mercados dinámicos.

Mientras más se perciban los costes de las fallas de mercado transaccional, mayor es la probabilidad de que las empresas multinacionales exploten sus ventajas competitivas a través de la producción internacional, más que de acuerdos contractuales con empresas extranjeras. Al contrario, mientras mayores sean los costes administrativos de operar una empresa extranjera, mayor es la probabilidad de que se prefieran acuerdos contractuales (o al menos una participación de capital compartido).

La decisión de dónde ubicar una empresa no es independiente de la propiedad de los activos o de la forma por la cual ellos o sus derechos son tramitados. La elección de una ubicación puede ser incitada por una falla de mercado como, por ejemplo, una falla de mercado espacial, mediante la imposición de barreras al comercio a un determinado país.

Las empresas deciden operar en los países extranjeros considerando el conjunto particular de ventajas de propiedad $(\mathrm{P})$ y localización (L) que enfrentan. El modo de entrada es seleccionado sobre las bases de las ventajas de la internalización (I) o la falta de estas (Rugman et al., 2011).

El paradigma ecléctico de la producción internacional no es una explicación de una empresa multinacional en forma individual. Su foco de interés siempre ha estado dirigido a explicar el nivel de las actividades de valor agregado extranjero de las empresas y/o de países (Dunning, 1991). Debe considerarse más un marco para analizar los determinantes de la producción internacional que como una teoría predictiva de la empresa multinacional. La teoría de la internalización es la más acorde para realizar un análisis a nivel empresa (Dunning, 1991).

\section{Críticas al paradigma ecléctico}

Las principales críticas al paradigma ecléctico son tres. Primero, a pesar de que a veces se ha representado al paradigma ecléctico con referencia a una empresa en particular, el principal foco de interés es la explicación de la producción internacional de todas las empresas, de un país particular o de un grupo de países. Por esto, se sostiene que no es correcto comparar los méritos y los deméritos del paradigma ecléctico directamente con los de la teoría de la internalización.

Segundo, Rugman (2010) ha expresado la crítica más fuerte al paradigma ecléctico, y ha afirmado que una ventaja de propiedad (P) podría ser en realidad derivada de una ventaja de internalización (I), en cuyo caso sería redundante considerar a estas dos variables como determinantes separados.

Tercero, se reconoce que el paradigma ecléctico, como es concebido originalmente, no es adecuado para abordar la dinámica de 
la producción internacional. Se sostiene, sin embargo, que puede ayudar a explicar por qué el perfil de inversión internacional de una industria o un país puede ser diferente en dos momentos distintos. Para relacionar los dos periodos se necesita introducir cambios en las variables exógenas y endógenas, incluida la estrategia, y observar cómo estos a su vez afectan la configuración de las ventajas de propiedad, localización e internalización.

\section{Contraste entre el paradigma ecléctico} y el modelo de internacionalización Upsala

Johanson y Vahlne (1990) desarrollaron las principales diferencias entre el paradigma ecléctico y el modelo de internacionalización Upsala, las mismas se pueden apreciar en la tabla 4.
La primera diferencia se da en cuanto a la localización de la producción, en donde el paradigma ecléctico predice que la producción se establece donde se pueda disfrutar de las ventajas OLI (por sus siglas en inglés: $\mathrm{O}=$ propiedad, $\mathrm{L}=$ localización, $\mathrm{I}=$ internalización), en tanto que el modelo de internacionalización Upsala toma en cuenta solo la distancia psíquica.

La segunda diferencia es respecto al valor explicativo. Para el paradigma ecléctico, el valor explicativo es alto en las últimas etapas del proceso de internacionalización (es decir, para las empresas globales), mientras que para el modelo Upsala es alto en las primeras etapas del proceso de internacionalización.

En términos de las variables explicativas, la tercera diferencia es aún mayor. El

\section{Tabla 4}

\section{Diferencias entre el paradigma ecléctico y el modelo de internacionalización Upsala}

\begin{tabular}{|l|l|l|}
\cline { 2 - 3 } \multicolumn{1}{c|}{} & \multicolumn{1}{c|}{ Paradigma ecléctico } & \multicolumn{1}{c|}{ Modelo Upsala } \\
\hline $\begin{array}{l}\text { Localización } \\
\text { de la producción }\end{array}$ & $\begin{array}{l}\text { Donde se puedan disfrutar de las venta- } \\
\text { jas OLI (O= propiedad; L= localización; } \\
\text { I= internalización) }\end{array}$ & $\begin{array}{l}\text { Sólo se toma en cuenta la distancia psí- } \\
\text { quica }\end{array}$ \\
\hline Valor explicativo & $\begin{array}{l}\text { Alto para las empresas globales, en las } \\
\text { últimas etapas del proceso de internacio- } \\
\text { nalización }\end{array}$ & $\begin{array}{l}\text { Alto en las primeras etapas del proceso } \\
\text { de internacionalización }\end{array}$ \\
\hline $\begin{array}{l}\text { Variables } \\
\text { explicativas }\end{array}$ & $\begin{array}{l}\text { Todos los factores exploratorios relevan- } \\
\text { tes para dar una explicación completa } \\
\text { de las operaciones en el extranjero de la } \\
\text { empresa }\end{array}$ & $\begin{array}{l}\text { Explícitamente el conocimiento de la } \\
\text { empresa }\end{array}$ \\
\hline $\begin{array}{l}\text { Estado } \\
\text { del modelo }\end{array}$ & $\begin{array}{l}\text { Estático, no puede explicar el proceso de } \\
\text { cambio de la producción internacional }\end{array}$ & Dinámico \\
\hline $\begin{array}{l}\text { Características } \\
\text { de los marcos }\end{array}$ & $\begin{array}{l}\text { Asume que los tomadores de decisiones } \\
\text { involucrados son racionales y están bien } \\
\text { informados desde el inicio del proceso de } \\
\text { internacionalización }\end{array}$ & $\begin{array}{l}\text { Reconoce que los costes de transacción } \\
\text { cambian a través del tiempo }\end{array}$ \\
\hline
\end{tabular}

Fuente: Elaboración propia. 
paradigma ecléctico tiene como objetivo dar una explicación completa de las operaciones de la empresa en el extranjero, confiando en todos los factores exploratorios relevantes. Por otro lado, el modelo de internacionalización Upsala, en su versión original, explícitamente usa solo una variable explicativa (el conocimiento de la empresa); implícitamente están las otras (relaciones con otros organismos en el mercado externo).

La cuarta diferencia es que el paradigma ecléctico es básicamente estático en naturaleza, no puede explicar el proceso de cambio de la producción internacional (Dunning, 1988), mientras que el modelo de internacionalización Upsala es dinámico, prestando explícita consideración a los cambios en las variables exploratorias a medida que avanza el proceso.

La quinta diferencia entre los dos marcos es que el paradigma ecléctico asume que los tomadores de decisiones involucrados son racionales y están bien informados desde el inicio del proceso de internacionalización, mientras que el modelo de internacionalización Upsala reconoce que los costes de transacción cambian a través del tiempo.

\section{Diferencia entre la teoría de la inter- nalización y el paradigma ecléctico}

Rugman (2010), en su escrito respecto a la reconciliación la teoría de la internalización y el paradigma ecléctico, planteó las principales diferencias de estas, las cuales se aprecian en la tabla 5 .

Buckley y Casson (1976) y Rugman (1981) - y otros estudiosos posteriores - han mostrado que la teoría de la internalización toma a la empresa como la unidad de análisis; las ventajas específicas de la empresa se producen obviamente a nivel de empresa y no a nivel de transacción. Por su parte, para explicar los patrones de IDE en el extranjero, la teoría ecléctica de Dunning toma como unidad de análisis la industria o el país (Rugman, 2010).

La teoría de la internalización realiza una explicación a nivel de empresa de la IDE, que puede centrarse en la toma de decisiones estratégicas de la empresa multinacional y es capaz de demostrar la heterogeneidad del comportamiento a nivel empresa dentro de la industria. Por su parte, la esencia de la teoría ecléctica es que las ventajas de propiedad (P), localización (L) e internalización (I) interactúan para producir una explicación de los patrones de IDE en el extranjero a nivel industrial.

La teoría de la internalización también se diferencia del paradigma ecléctico en el tratamiento del modo de entrada. Con la teoría de la internalización, la empresa multinacional puede seleccionar expandirse hacia el exterior a través de la IDE (reteniendo la ventaja específica de la empresa basada en el conocimiento), o puede seleccionar otra forma de entrada, como una licencia, alianzas estratégicas u otras alianzas (todo lo cual conduce a una posible disipación del conocimiento basado en la ventaja específica de la empresa multinacional). El tratamiento del modo de entrada en el paradigma ecléctico es mucho más amplio, y teóricamente menos preciso.

La visión basada en recursos ( $R B V$, por sus siglas en inglés: Resource Based View) 
requiere un enfoque sobre las capacidades a nivel empresa, es decir, las ventajas específicas de la empresa de la teoría de la internalización. El paradigma ecléctico es incoherente con la visión basada en recursos de la empresa. La RBV no consideraría los atributos, a nivel de país, generalmente disponibles, tales como el trabajo, los recursos naturales y el entorno institucional como capacidades específicas de la empresa.

La diferencia fundamental entre la teoría de la internalización y el paradigma ecléctico se da debido al uso de las ventajas de propiedad de Dunning (1980). Dunning incluye en las ventajas de la propiedad no solo las capacidades a nivel empresa, sino también los recursos y capacidades del país de origen. Dunning explícitamente sostuvo que las ventajas de propiedad $(\mathrm{P})$ incluyen activos específicos de la empresa, activos intangibles como el conocimiento, las habilidades organizativas y de gestión, los nombres de marcas, etc. Pero luego sostuvo que las ventajas de propiedad (P) también incluyen factores institucionales del país de origen, como el entorno cultural y legal, y los activos tangibles, como la mano de obra y los recursos naturales. Esta es una de las principales críticas que se le hace al paradigma ecléctico; para que el paradigma ecléctico se reconcilie con la teoría de la internalización es necesario que abandone el tratamiento de las ventajas de propiedad como una categoría separada. En su lugar, los componentes específicos de la empresa de las ventajas de propiedad (P) deberían ser incorporados con la ventaja de internalización (I), y las ventajas de propiedad $(\mathrm{P})$ a nivel país serían mejor tratadas como ventajas de localización (L).

\section{Enfoque de red}

Ruzzier et al. (2006) consideran este enfoque dentro de los modelos no tradicionales de internacionalización. El enfoque de red da importancia a las redes intraorganizacionales e interorganizacionales, a los fines de un proceso de internacionalización exitoso.

Las multinacionales están envueltas en un amplio conjunto de interacciones, las que condicionan sus estrategias. Todo el entramado de relaciones comerciales, informativas y sociales que, bien directa o indirectamente, conectan los diferentes miembros pertenecientes a un sistema industrial, definen lo que se conoce como una red o network (Plá y León, 2014).

Por su parte, Coviello y Munro (1997) señalan que las pymes muestran un patrón de externalización de sus actividades durante los procesos de internacionalización, dependiendo en gran medida del establecimiento de relaciones de red para seleccionar el mercado y el modo de entrada. También afirman que tanto el grado como la forma de la internacionalización están influenciados por diferentes tipos de relaciones que son desarrolladas en las redes.

Para construir relaciones financieras, tecnológicas y de mercado con los otros miembros de las redes, la empresa extiende sus conexiones con otras empresas; de esta forma incrementa sus actividades dentro del mercado nacional hasta que se convierten en internacionales. Las relaciones de red pueden facilitar o inhibir las actividades de desarrollo de producto 
y diversificación de mercado. Las redes existentes de los directivos, así como su habilidad para establecer nuevas relaciones de red, deberían ser consideradas como una capacidad competitiva clave.

En relación con la internacionalización de la empresa, la visión de red argumenta que la empresa internacionalizada está inicialmente comprometida en una red que es principalmente nacional. En términos de redes, la internacionalización significa que la empresa desarrolla relaciones de negocios en redes en otros países. Estas se pueden alcanzar (1) a través del establecimiento de relaciones en redes en países que sean nuevas para la empresa (extensión internacional), (2) a través del desarrollo de relaciones en dicho mercado (penetración), y (3) a través de la conexión de redes en países diferentes (integración internacional).

Tanto el modelo Upsala como el paradigma ecléctico se concentran en la autonomía de la empresa en el desarrollo de su actividad. La mayor debilidad es el enfoque unilateral sobre las actividades del fabricante, junto con el intermediario, en el flujo de bienes y servicios para el cliente.

En contraste, el enfoque de red describe el sistema industrial como una red de

Tabla 5

Diferencias entre el paradigma ecléctico y la teoría de la internalización

\begin{tabular}{|c|c|c|}
\hline & Teoría de la internalización & Paradigma ecléctico \\
\hline Unidad de análisis & Empresa & Industria, país \\
\hline Nivel de explicación & Explicación a nivel de empresa de la IDE & $\begin{array}{l}\text { Las ventajas de propiedad (P), localización } \\
\text { (L) e internalización (I) interactúan para } \\
\text { producir una explicación de los patrones de } \\
\text { la IDE en el extranjero a nivel industrial }\end{array}$ \\
\hline Modo de entrada & $\begin{array}{l}\text { Expandirse hacia el exterior a través de } \\
\text { la IDE (reteniendo la ventaja específica } \\
\text { de la empresa), u otra forma de entrada, } \\
\text { como licencia, alianzas estratégicas, o } \\
\text { alianzas (disipación de la ventaja especí- } \\
\text { fica de la empresa) }\end{array}$ & Tratamiento amplio \\
\hline $\begin{array}{l}\text { Visión basada en recur- } \\
\text { sos (RBV) }\end{array}$ & $\begin{array}{l}\text { Coherente con la RBV, considera las ven- } \\
\text { tajas específicas de la empresa }\end{array}$ & $\begin{array}{l}\text { Incoherente con la RBV de la empresa, ya que } \\
\text { considera los atributos a nivel país }\end{array}$ \\
\hline Ventaja de propiedad & $\begin{array}{l}\text { Abandona el tratamiento separado de } \\
\text { las ventajas de propiedad como una ca- } \\
\text { tegoría separada. Incluye a los compo- } \\
\text { nentes específicos de la empresa de las } \\
\text { ventajas de propiedad (P) dentro de la } \\
\text { ventaja de internalización (I), e incluye a } \\
\text { las ventajas de propiedad (P) a nivel país } \\
\text { dentro de la ventaja de localización (L) }\end{array}$ & $\begin{array}{l}\text { Incluye dentro del mismo concepto de ven- } \\
\text { taja de propiedad a los activos específicos de } \\
\text { la empresa y a los factores institucionales del } \\
\text { país de origen. }\end{array}$ \\
\hline
\end{tabular}

Fuente: Elaboración propia. 
empresas a través de la cual se establecen, desarrollan y mantienen relaciones comerciales duraderas. La interpretación de este entorno por los directivos de la empresa proveedora informará la decisión sobre a qué países ingresar y a qué clientes proveer, e impulsará la estructura de la organización para la entrada en el mercado. La empresa tendrá que tener en cuenta y evaluar no solo su propia posición en relación con sus clientes en un mercado dado, sino también el entorno del mercado en relación con otros actores (Johanson y Vahlne, 1977).

El entendimiento del proceso de internacionalización de las pequeñas empresas puede ser mejorado integrando los modelos de internacionalización incremental con la perspectiva de red. Esta integración es de particular importancia dado que la perspectiva de red introduce un elemento multilateral más al proceso unilateral encontrado en los modelos tradicionales de internacionalización incremental (Johanson y Vahlne, 1990). Por un lado, la visión de etapas sugiere una evolución hacia la internacionalización basada en el aprendizaje cognitivo y el desarrollo de competencias que aumenta, a través de la experiencia, con el tiempo. Por otro lado, la perspectiva de red muestra que las actividades de desarrollo del mercado internacional surgen de, y están conformadas por, una red externa de relaciones formales e informales (Coviello y Munro, 1997).

Johanson y Mattsson (1993) explican el proceso de internacionalización de las empresas a partir de la intersección de las ventajas competitivas de la empresa y aquellas correspondientes a las redes.
De acuerdo con estos autores, la empresa establece y desarrolla posiciones en los mercados foráneos dependiendo de sus características, según la empresa esté o no altamente internacionalizada y el grado de internacionalización de la red a la que pertenece.

\section{Enfoque de emprendimiento in- ternacional}

El emprendimiento internacional es un área de investigación emergente (Antoncic y Hisrich, 2001). El concepto de emprendimiento internacional ha evolucionado durante las últimas décadas y el interés académico en el tema ha ido creciendo. Una primera definición se centró en las actividades internacionales de nuevas empresas con exclusión de las empresas establecidas (McDougall, 1989). Más adelante, McDougall y Oviatt (200o) ofrecieron una lista más inclusiva de temas relacionados con el emprendimiento internacional, en la que se reconoce la importancia de este fenómeno en las empresas establecidas. La inclusión de este tipo de empresas corrige un descuido en el campo del emprendimiento: la presunción de que estas empresas no son innovadoras y se rehúsan a tomar riesgos. Con la globalización de la economía, el interés en el emprendimiento internacional ha crecido rápidamente.

Los temas de emprendimiento y de negocios internacionales coinciden con una frecuencia cada vez mayor en los esfuerzos de investigación. Los investigadores de los negocios internacionales están ampliando su enfoque tradicional de grandes empresas multinacionales para también incluir a 
empresas emprendedoras en su agenda de investigación (McDougall y Oviatt, 200o).

Esto ha dado lugar al surgimiento de uno de los últimos enfoques de la internacionalización de las pymes: el «enfoque de emprendimiento internacional» (McDougall y Oviatt, 1997; Antoncic y Hisrich, 2001; Ruzzier et al., 2006), que representa una nueva área de investigación en la interfaz de la investigación de emprendedurismo y de negocios internacionales. Al igual que el enfoque de red, Ruzzier et al. (2006) considera este enfoque dentro de los modelos no tradicionales de internacionalización.

El concepto de emprendimiento internacional se originó cuando los avances tecnológicos permitieron a las nuevas empresas acceder a los mercados extranjeros sin explotar. Internet ha abierto las oportunidades comerciales de una manera que no era posible en el momento del desarrollo de las anteriores teorías sobre el proceso de internacionalización de empresas (Crick, 2009).

Es importante resaltar el papel que tiene el emprendedor en este enfoque. El emprendedor, como tomador de decisiones de la empresa, es clave en la internacionalización de la pyme. McDougall, Shaney Oviatt (1994) definen al emprendedor como un individuo que es más consciente de las oportunidades que otros, capaz de aprovechar sus capacidades de información para crear ventajas competitivas antes de que los demás tomen conciencia de tales oportunidades. Señalan que los emprendedores exitosos son aquellos capaces de prever oportunidades de ganancias de desequilibrio cuando las encuentren. Knight y Cavusgil (2004) sostienen que la visión global del emprendedor puede ser explicada por la influencia de su tipo, su nivel de educación y su experiencia previa. La reputación, las capacidades y la habilidad de asumir riesgos de los emprendedores dinámicos ayudan a sus empresas a buscar la internacionalización antes o después y a expandir sus operaciones internacionales más rápidamente (Knight y Cavusgil, 2004, 2015). Fernández-Ortiz y Lombardo (2009) sostienen que el emprendedor es más flexible, tiene una mayor capacidad de visión internacional de negocios, así como mayor cultura internacional y tolerancia al riesgo, y mayor capacidad para el desarrollo de negocios internacionales.

La visión económica (teoría de la internalización y paradigma ecléctico) es útil para establecer plantas de producción únicas durante las etapas posteriores de la internacionalización de la empresa, pero ignora el proceso de la internacionalización. El enfoque de proceso (modelo Upsala y modelo de innovación) tiene en cuenta el proceso de internacionalización, pero al igual que el enfoque económico pasa por alto la posibilidad de que los individuos tomen decisiones estratégicas (Reid, 1983) y es menos apropiado para entender el cambio estratégico radical, donde los empresarios y los altos directivos juegan un papel importante.

Por lo antes dicho, es innegable la importancia de los emprendedores en la internacionalización de las pymes (muchas veces el emprendedor es entendido como el fundador o el directivo de la empresa, por lo que en esta investigación se lo abordará de manera análoga). Sin embargo, para crear mayor valor, las empresas emprendedoras también deben actuar estratégicamente, y esto requiere una integración del 
pensamiento emprendedor y estratégico. Los emprendedores pueden ser vistos como personas estratégicas que encuentran una relación entre lo que la empresa puede hacer dentro del universo de lo que podría hacer.

En la tabla 6 se muestran distintas definiciones de emprendimiento internacional.

De todas las definiciones del emprendimiento internacional, la más apropiada para la presente investigación es la expuesta por Zahra y George (2002:11), quienes lo definen como el proceso de «descubrir creativamente y explotar las oportunidades que se encuentran fuera de los mercados internos de una empresa en la búsqueda de una ventaja competitiva».

Esta definición destaca la importancia del reconocimiento de oportunidades, el descubrimiento y la explotación como una característica distintiva del emprendimiento. El término creatividad, incluido

\section{Tabla 6}

\section{Definiciones de emprendimiento internacional}

\begin{tabular}{|l|l|}
\hline \multicolumn{1}{|c|}{ Autor } & \multicolumn{1}{|c|}{ Definición } \\
\hline McDougall (1989) & $\begin{array}{l}\text { Desarrollo de nuevas empresas o start-ups internacionales que, desde sus } \\
\text { inicios, se involucran en negocios internacionales, viendo así su dominio } \\
\text { operativo como internacional desde las etapas iniciales de la operación de } \\
\text { la empresa. }\end{array}$ \\
\hline Zahra (1993) & $\begin{array}{l}\text { El estudio de la naturaleza y las consecuencias del comportamiento de } \\
\text { toma riesgo de una empresa a medida que se aventura en los mercados } \\
\text { internacionales. }\end{array}$ \\
\hline Oviatt y McDougall (1994) & $\begin{array}{l}\text { Una organización empresarial que, desde el inicio, busca obtener una ventaja } \\
\text { competitiva significativa del uso de los recursos y la venta de productos en } \\
\text { múltiples países. }\end{array}$ \\
\hline Wright y Ricks (1994) & $\begin{array}{l}\text { Es una actividad a nivel de empresa que cruza las fronteras nacionales y se } \\
\text { centra en la relación entre las empresas y los entornos internacionales en los } \\
\text { que operan. }\end{array}$ \\
\hline $\begin{array}{l}\text { McDougall y Oviatt, (1997, } \\
\text { p. 293) }\end{array}$ & $\begin{array}{l}\text { Actividades nuevas e innovadoras que tienen como objetivo la creación de } \\
\text { valor y el crecimiento de las organizaciones empresariales a través de las } \\
\text { fronteras nacionales. }\end{array}$ \\
\hline $\begin{array}{l}\text { McDougall y Oviatt (200o, } \\
\text { p. 903) }\end{array}$ & $\begin{array}{l}\text { Combinación de comportamiento innovador, proactivo y de búsqueda de } \\
\text { riesgos que cruza las fronteras nacionales y tiene la intención de crear valor } \\
\text { en las organizaciones. }\end{array}$ \\
\hline Zahra y George (2002) & $\begin{array}{l}\text { Proceso de descubrir creativamente y explotar las oportunidades que se } \\
\text { encuentran fuera de los mercados internos de una empresa en la búsqueda de } \\
\text { una ventaja competitiva. }\end{array}$ \\
\hline Oviatt y McDougall (2005) & $\begin{array}{l}\text { Descubrimiento, promulgación, evaluaciónyla explotacióndeoportunidades, } \\
\text { a través de las fronteras nacionales, para crear bienes y servicios futuros. }\end{array}$ \\
\hline Oviatt y McDougall (2005) & $\begin{array}{l}\text { Empresas que están persiguiendo actividades innovadoras a través de las } \\
\text { fronteras, independientemente de su edad y tamaño. }\end{array}$ \\
\hline
\end{tabular}

Fuente: Elaboración propia. 
en la definición, refuerza la necesidad de innovación en la forma que una empresa descubre o explota oportunidades. Las empresas que internacionalizan sus operaciones de una forma innovadora y creativa pueden lograr ganancias significativas que van más allá del desempeño financiero superior.

En la práctica, el emprendimiento está presente en organizaciones grandesy pequeñas bien establecidas, y es un elemento importante de su desarrollo organizativo y económico. El énfasis en el rol de la orientación emprendedora internacional presagió lo que es ahora una visión más ampliamente aceptada sobre el rol crítico de la orientación emprendedora en el apoyo a la internacionalización de las empresas jóvenes.

La globalización y la hipercompetición han llevadoa un nuevo fenómeno de internacionalización de las startups, que representa un desafío a los enfoques tradicionales de internacionalización. Especialmente en este nuevo fenómeno y en las pymes en general, tienen una posición prominente los emprendedores en forma individual, sus factores personales y sus relaciones.

Antoncic y Hisrich (2001) han propuesto un modelo conceptual que intenta unir los modelos tradicionales con el área emergente de las startups internacionales, el que se presenta en la figura 1. Los conceptos clave del modelo de emprendimiento internacional de Antoncic y Hisrich (2001) son la internacionalización, sus antecedentes y consecuencias.

El modelo de emprendimiento internacional resultante está centrado en el concepto de la internacionalización, que incluye las dimensiones de tiempo de la internacionalización, modo de la internacionalización y rendimiento de la internacionalización. El modelo contiene los bloques de antecedentes clave (características de la empresa y del entorno) y el bloque de consecuencias representado por el rendimiento de la empresa.

El tiempo de la internacionalización es una propiedad crucial, porque vincula la investigación de internacionalización sobre las pymes que son internacionales desde el inicio y las que se internacionalizan más adelante en la vida de la empresa. El número de empresas que ingresan en los mercados extranjeros cerca del momento de su creación ha aumentado rápidamente; estas nuevas empresas comienzan con una estrategia internacional proactiva que implica que se tomó la decisión de entrada al mercado internacional antes del inicio de la empresa (Oviatt y McDougall, 1994).

El modo de internacionalización se refiere a la intensidad de involucramiento en las operaciones internacionales en términos de intensidad de inversión extranjera, que va desde la no participación hasta empresas de propiedad total. No hay una estrategia de entrada ideal, se pueden adoptar diferentes modos de entrada al mercado.

El rendimiento de la internacionalización se refiere a la extensión y al crecimiento de las ventas internacionales. Los dos criterios de rendimiento de exportación más frecuentemente utilizados son la intensidad de la exportación - porcentaje de ventas contabilizadas por exportación-y el crecimiento de las ventas de exportación (Aaby y Slater, 1989). 
Las características de la empresa se pueden agrupar en siete puntos. El primero es el tamaño de la empresa, que puede influir en el proceso de internacionalización. El segundo es la estrategia, ya que las estrategias de diferenciación de producto y de mercados pueden estar positivamente relacionadas con la internacionalización. El tercero es la experiencia internacional, que puede influir en la elección del modo de entrada de la empresa en el mercado extranjero, dado que en el caso de las empresas menos experimentadas es más probable que elijan modos de entrada de no inversión como la exportación. El cuarto es el compromiso de la gestión a la internacionalización, las actitudes, las percepciones y las expectativas tienden a estar positivamente relacionadas con la propensión a la exportación (Aaby y Slater, 1989). El quinto son las diferentes redes organizativas y personales. El sexto son las características de los fundadores y directivos de la empresa, incluyendo características demográficas como la edad y el nivel de educación. El séptimo punto se refiere a las características particulares de la empresa, como la antigüedad y la cultura organizativa.

Las características del entorno que pueden influir en la internacionalización incluyen las del mercado nacional, como el tamaño, el grado de inmigrantes de un país, la competitividad interna; las características del mercado extranjero, como la proximidad del mercado, el potencial y el riesgo de inversión de un país específico; la condición de mercado internacionalizado (la velocidad de internacionalización puede ser mucho más alta en mercados internacionalizados); y la industria en la cual compite la empresa.
Las consecuencias del proceso de internacionalización se representan por el rendimiento de la empresa en términos de crecimiento y rentabilidad, lo cual es el resultado último que indica si la internacionalización finalmente es rentable o no.

Este modelo se centró en la construcción de una teoría de emprendimiento internacional en lugar de la construcción de teorías parciales del rendimiento exportador de las pymes o de las nuevas empresas internacionales (Antoncic y Hisrich, 2001).

El nuevo modelo conceptual de emprendimiento internacional (Ruzzier et al., 2006), basado en el modelo originalmente propuesto por Antoncic y Hisrich (2001), representa la integración conceptual de la corriente teórica más tradicional con algunas teorías más nuevas (Ruzzier, Antoncic, y Hisrich, 2007). Este nuevo modelo está representado en la figura 2.

Son cuatro las principales modificaciones de su forma original. En primer lugar, las características del fundador/ directivo, que previamente partían de las características de la empresa, ahora son analizadas separadamente y divididas en capital humano y capital social. Segundo, la internacionalización consiste en cuatro dimensiones principales (modo, mercado, tiempo y producto) en lugar de dos, más el rendimiento internacional. Tercero, se seleccionaron parámetros diferentes de las características de la empresa, en el modelo anterior eran sietey en el actual quedaron solo dos. Cuarto, las características del entorno se redujeron a dos, el entorno nacional y el entorno internacional. 
El capital humano se refiere a una variedad de habilidades y conocimiento valioso que una persona ha acumulado a través del tiempo. Los factores personales de los emprendedores (fundador/directivo) son una influencia importante en la internacionalización de las pymes.

Las habilidades de negocios internacionales son adquiridas por el emprendedor a través de la experiencia en los mercados extranjeros, la experiencia internacional del emprendedor es un recurso inimitable e irremplazable de las empresas. La orientación internacional es la exposición del emprendedor a las culturas extranjeras a través de vivencias, trabajos o viajes al extranjero; es un factor potencialmente importante que podría diferenciar a las empresas con relación a su propensión a la exportación, agresividad, desarrollo y rendimiento. La percepción del entorno se entiende como la percepción de riesgo; la propensión a internacionalizar se relaciona positivamente con el nivel de tolerancia al riesgo del emprendedor, de manera que es más probable que los emprendedores tomadores de riesgo respondan favorablemente a las oportunidades de exportación. El conocimiento de gestión es la capacidad de introducir mejores prácticas de recursos humanos, emprender estrategias competitivas más prometedoras e identificar mejores oportunidades en los mercados extranjeros. La combinación de estos componentes definitorios de capital humano se relaciona positivamente a la internacionalización de la pyme.

Dentro del nuevo modelo de las dimensiones ya explicadas de tiempo, modo y rendimiento de la internacionalización, las nuevas dimensiones son el mercado y el producto. Los mercados objetivos pueden diferir significativamente entre sí y del mercado del país de origen. Esas diferencias afectan esencialmente la determinación de la estrategia de la empresa en los mercados objetivos; es importante considerar la distancia

Figura 1

Modelo de emprendimiento internacional (2001)

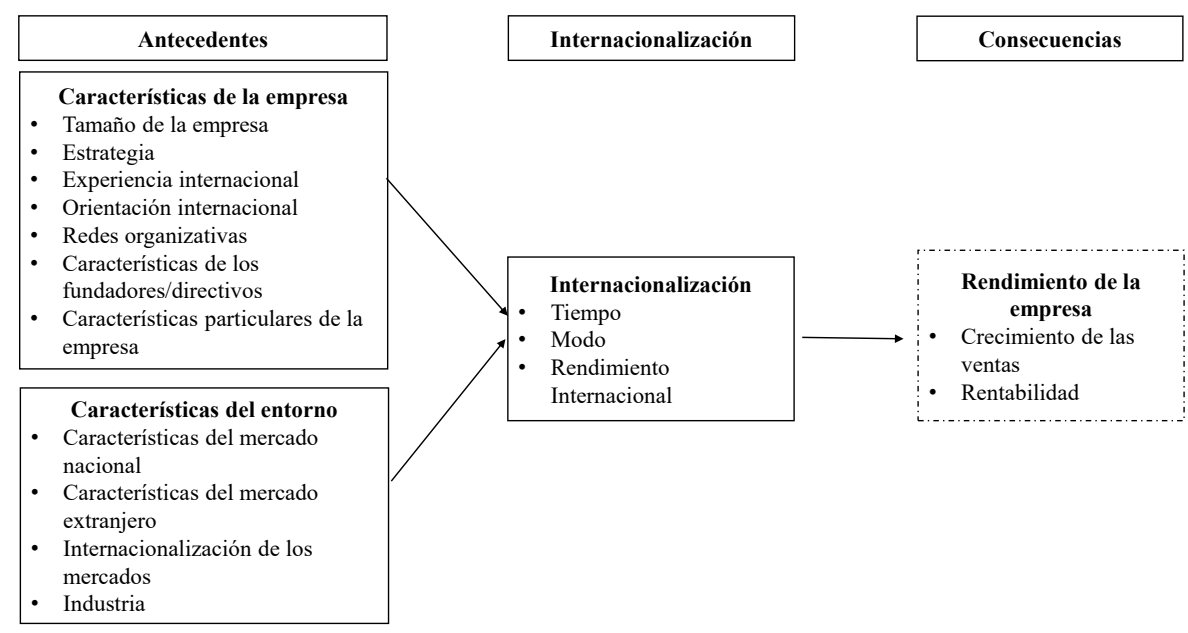

Fuente: Elaboración propia. 
psíquica y geográfica entre el mercado origen y el mercado objetivo. Luostarinen (1979) desarrolló una clasificación de la variable producto, productos que pueden ser bienes físicos, servicios, know-how y sistemas. Para desarrollar una medida válida de internacionalización de la pyme, la dimensión de rendimiento tiene que ser consistente con el concepto multidimensional que representa el grado de internacionalización, contemplando las diferentes dimensiones de internacionalización: modo, mercado, productoy tiempo. En el futuro, dimensiones adicionales como cultura, tecnología, industria o mercados locales específicos podrían complementary enriquecer el constructo con hallazgos adicionales dentro del fenómeno de la internacionalización.

El modelo de emprendimiento internacional le otorga más importancia al emprendimiento y a los emprendedores (y sus características) y otorga mayor jerarquía a la dimensión tiempo.

La principal limitación de los modelos presentados en su versión inicial (Antoncic y Hisrich, 2001; Ruzzier, Hisrich, y Antoncic, 2006) es que, si bien abarcan varias dimensiones, no son exhaustivos y no abordan específicamente las interacciones entre los constructos que lo componen.

Existe un rol crítico de la orientación emprendedora en el apoyo a la internacionalización de las jóvenes empresas (Knight y Cavusgil, 2015). La orientación emprendedora apoya no solo el lanzamiento precoz de la empresa internacional, sino también el desarrollo de estrategias y tácticas necesarias para un rendimiento internacional (Knight y Cavusgil, 2004).
Las empresas emprendedoras están inclinadas, más que otras, a crear y activar estrategias y maniobrar tácticas con la visión de mantener o mejorar el rendimiento internacional. La orientación emprendedora internacional facilita un enfoque proactivo para lidiar con entornos riesgosos y una visión internacionalista abierta al mundo (Knight y Cavusgil, 2005).

\section{Conclusiones}

El tema de la internacionalización de empresas ha suscitado abundante interés en la literatura especializada. El presente trabajo revisa las teorías tradicionales (modelo Upsala y modelo de innovación), las perspectivas teóricas dominantes de la evolución multinacional (teoría de la internalización y paradigma ecléctico) y las teorías no tradicionales (enfoque de red y enfoque de emprendimiento internacional).

Entre las diferentes aproximaciones al concepto de internacionalización, destaca la definición de Petri Ahokangas (1998). Este autor enfatiza la importancia de los recursos y señala que la internacionalización es «el proceso de movilización, acumulación y desarrollo de reservas de recursos para actividades internacionales».

Las teorías tradicionales de internacionalización se formulan tomando el comportamiento de las empresas en los años sesenta; ignoran el impacto de las variables externas y prestando poca atención a la dimensión tiempo. Por su parte, las perspectivas teóricas dominantes de la evolución multinacional fueron postuladas posteriormente considerando el 
Figura 2

Nuevo modelo de emprendimiento internacional (2006)

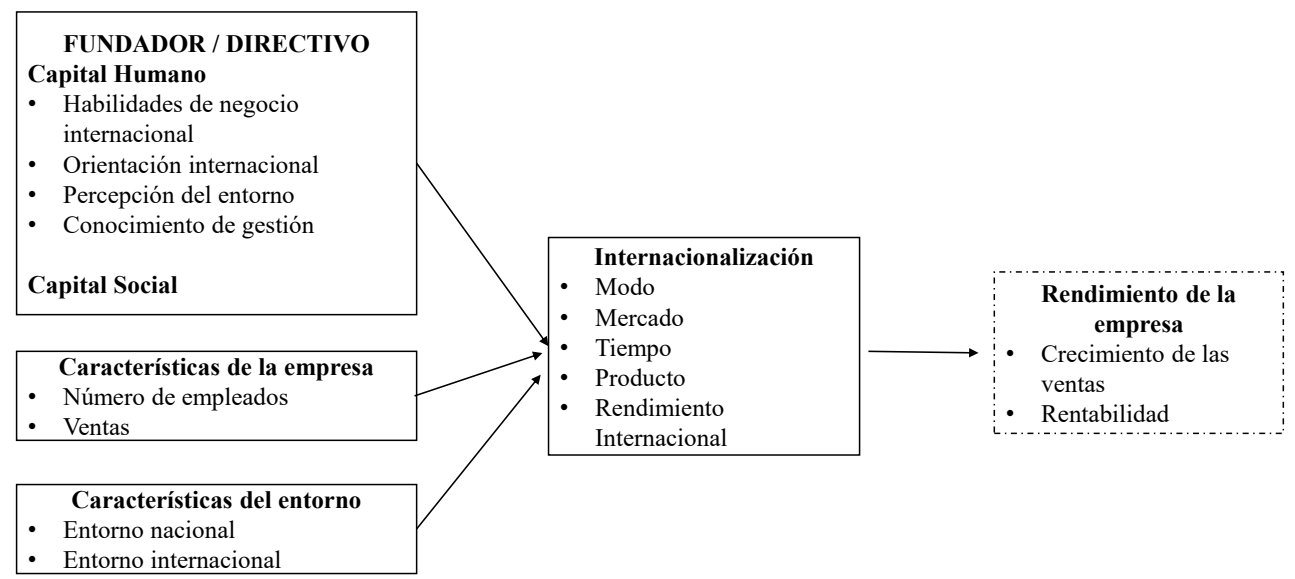

Fuente: Elaboración propia.

tamaño del mercado. La perspectiva de red introduce un elemento multilateral más al proceso unilateral encontrado en los modelos tradicionales de internacionalización incremental; señala que las actividades de desarrollo del mercado internacional surgen de, y están conformadas por, una red externa de relaciones formales e informales de la empresa. El enfoque de emprendimiento internacional incluye a las empresas emprendedoras o startups, ampliando el enfoque tradicional de las grandes empresas multinacionales estudiado desde siempre por los investigadores en negocios internacionales.

Los avances tecnológicos favorecidos por el actual proceso de globalización permitieron que las empresas accedan de forma más fácil a los mercados internacionales, reduciendo sus costes de transacción y aprendizaje en la expansión internacional. Internet produjo una apertura de oportunidades para todas las empresas, independientemente de su edad y tamaño, que no era posible en el momento del desarrollo de las anteriores teorías tradicionales de internacionalización.

Se requiere el desarrollo de nuevas teorías de internacionalización, en donde se tenga presente el análisis de la dimensión de tiempo, el rol del emprendedor y el avance tecnológico en el proceso de internacionalización; de esta forma se abarcaría el estudio de nuevos modelos de negocios como, por ejemplo, los de empresas como Born Global o como las nuevas empresas emergentes denominadas empresas "unicornio", cada vez más presentes en los mercados globales y que, sin embargo, han sido poco abordadas por la literatura de negocios, ya sea que se presenten en mercados desarrollados o en mercados en desarrollo. Resulta también importante estudiar cómo estos nuevos modelos de negocios se internacionalizan de forma diferente, usando diferentes métodos de entrada en los mercados internacionales. 


\section{Referencias}

Aaby, N. E., y Slater, S. F. (1989). Management influences on export performance: a review of the empirical literature 1978 1988. International marketing review, 6(4).

Ahokangas, P. (1998). Internationalization and resources: an analysis of processes in Nordic SMSs. Doctoral dissertation. Vaasa: Universitas Wasaensis.

Andersen, O. (1993). On the internationalization process of firms: A critical analysis. Journal of international business studies, 24(2), 209-231.

Almodóvar, P., y Rugman, A. M. (2014). The $M$ curve and the performance of Spanish international newventures. British Journal of Management, $25(\mathrm{~S} 1)$.

Antoncic, B., y Hisrich, R. D. (2001). An integrative conceptual model. Journal of Euromarketing, 9(2), 17-35.

Barney, J. (1991). Firm resources and sustained competitive advantage. Journal of management, 17(1), 99-120.

Beamish, P. W. (1990). The internationalization process for smaller Ontario firms: A research agenda. Research in global business management, 1, 77-92.

Benito, G. R. G., y Gripsrud, G. (1992). The expansion of foreign direct investments - Discrete Rational Location Choices or a Cultural LearningProcess. Journal of International Business Studies, 23, 461-476.

Bilkey, W. J., y Tesar, G. (1977). The Export Behavior of Smaller-Sized Wisconsin Manufacturing Firms. Journal of International Business Studies, 8(1), 93-98

Bose, T. K. (2016). Critical success factors of SME internationalization. Journal of Small Business Strategy Peoria, 26(2) 87-109.

Buckley, P. y Casson, M. (1976). The future of the multinational Enterprise. Basinstoke: Macmillan.

Buckley, P. J., y Casson, M. C. (2009). The internalization theory of the multinational enterprise: A review of the progress of a research agenda after 30 years. Journal of International Business Studies, 40(9), 1563-1580.

Calof, J. L., y Beamish, P. W. (1995). Adapting to foreign markets: Explaining internationalization. International business review, 4(2), 115-131.

Cavusgil, S. T. (1980). On the internationalization process of firms. European Research, 8 (November): 273-281.

Chetty, S.,y Campbell-Hunt, C. (2004). Astrategicapproach tointernationalisation:atraditional versus a «born-global» approach. Journal of International Marketing, 12(1), 57-81.

Coviello, N., y Munro, H. (1997). Network relationships and the internationalisation process of small software firms. International Business Review, 6(4), 361-386.

Crick, D. (2009). The internationalisation of bornglobal and international new venture SMEs. International Marketing Review, 26(4/5), 453-476.

Czinkota, M. R. (1982). Export development strategies: US promotion policies. New York: Praeger Publishers.

Dunning, J. H. (1977). Trade, location of economic activity and the MNE: A search for an eclectic approach. En The international allocation of economic activity (pp. 395-418). Londres: Palgrave Macmillan. Dunning, J. H. (1980). Toward an eclectic theory of international production: Some 
empirical tests. Journal of international business studies, 11(1), 9-31.

Dunning, J. H. (1988). Theeclectic paradigm of international production: A restatement and some possible extensions. Journal of international business studies, 19(1), 1-31.

Dunning, J. H. (1991). The eclectic paradigm of international production. The nature of the transnational firm. Londres: Routledge.

Fernández-Ortiz, R., y Lombardo, G. F. (2009). Influence of the capacities of top management on the internationalization of SMEs. Entrepreneurship and Regional Development, 21(2), 131-154.

Hitt, M. A., Ireland, R. D., y Hoskisson, R. E. (2007). Strategic management: Globalization and competitiveness. Mason, $\mathrm{OH}$ : Thomson South-Western. Hymer, S. H. (1976). International operations of national firms. MIT press.

Johanson, J., y Mattsson, L. G. (1993). Internationalization in industrial systems - a networkapproach, strategies in global competition. En P.J. Buckleyy P. N. Ghauri (Eds.), The Internationalization of the Firm:A Reader. Londres:Academic Press. Johanson, J., y Wiedersheim-Paul, F. (1975). The internationalization of the firm - four Swedish cases. Journal of management studies, 12(3), 305-323.

Johanson, J., y Vahlne, J. E. (1977). The internationalization process of the firm - a model of knowledge development and increasing foreign market commitments. Journal of international business studies, 23-32.

Johanson, J., y Vahlne, J. E. (1990). The mechanism of internationalization. International marketing review, 7(4).

Johanson, J., y Vahlne, J. E. (2009). The Uppsala internationalization process model revisited: from liability of foreignness to liability of outsidership. Journal of international business studies, 40(9), 1411-1431.

Johanson, J., y Vahlne, J. E. (2017). From internationalization to evolution: The Uppsala model at 40 years. Journal of International Business Studies, 48(9), 1087-1102.

Jones, M. V., Coviello, N., y Tang, Y. K. (2011). International entrepreneurship research (1989-2009): a domain ontology and thematic analysis. Journal of business venturing, 26(6), 632-659.

Knight, G. A., y Cavusgil, S. T. (1996). The born global firm: A challenge to traditional internationalization theory. Advances in International Marketing; Bingley 8, 11-26.

Knight, G. A., y Cavusgil, S. T. (2004). Innovation, organizational capabilities, and the born-global firm. Journal of international business studies, 35(2), 124-141.

Knight, G. A., y Cavusgil, S. T. (2005). A taxonomy of born-global firms. MIR: Management International Review, 15-35.

Knight, G. A., y Cavusgil, S. T. (2015). The born global firm: An entrepreneurial and capabilities perspective on early and rapid internationalization. Journal of International Business Studies, 46(1), p. 3-16

Lehtinen, U., y Penttinen, H. (1999). Definition of the internationalization of the firm. Perspectives on Internationalization. Helsinki: Helsinki School of Economics and Business Administration.

Luostarinen, R. (1979). Internationalization of the firm: an empirical study of the 
internationalization of firms with small and open domestic markets with special emphasis on lateral rigidity as a behavioral characteristic in strategic decision making. Helsinki: Helsinki School of Economics.

McDougall, P. (1989). International versus domestic entrepreneurship: new venture strategic behavior and industry structure. Journal of Business Venturing, 4(6), 387-400.

McDougall, P., y Oviatt, B. M. (1997). International entrepreneurship literature in the 1990 and directions for future research. Entrepreneurship 2000, 291-320.

McDougall, P., y Oviatt, B. M. (200o). International entrepreneurship: the intersection of two research paths. Academy of Management Journal, 43(5), 902-906.

McDougall, P., Shane, S., y Oviatt, B. M. (1994). Explaining the formation of international new ventures: The limits of theories from international business research. Journal of business venturing, 9(6), 469-487.

Narula, R., y Verbeke, A. (2015). Making internalization theory good for practice: The essence of Alan Rugman>s contributions to international business. Journal of World Business, 5o(4), 612-622.

Oviatt, B. M., y McDougall, P. (1994). Toward a Theory of International New ventures. Journal of International Business Studies, 25(1), 45-64.

Oviatt, B. M., y McDougall, P. (2005). Defining international entrepreneurship and modelling the speed of internationalization. Entrepreneurship Theory and Practice, 29(5), 537-554.
Plá, J., y León, F. (2016). Dirección internacional de la empresa. McGraw-Hill Education.

Reid, S. D. (1981). The decision-maker and export entry and expansion. Journal of International Business Studies, 12 (Fall): 101-12.

Reid, S. D. (1983). Firm Internationalization, Transaction Costs and Strategic Choice. International Marketing Review, 1(2).

Rugman, A. M. (1981). New theories of the multinational enterprise. New York: St. Martin`s Press.

Rugman, A. M. (2010). Reconciling internalization theory and the eclectic paradigm. Multinational Business Review, 18(2), 1-12.

Rugman, A. M., y Verbeke, A. (1992). A note on the transnational solution and the transaction cost theory of multinational strategic management. Journal of international business studies, 23(4), 761-771.

Rugman, A. M., y Verbeke, A. (2003). Extending the theory of the multinational enterprise: Internalization and strategic management perspectives. Journal of International Business Studies, 34(2), 125-137.

Rugman, A. M., y Verbeke, A. (2008). Internalization theory and its impact on the field of international business. En International Business Scholarship: AIB Fellows on the First 50 Years and Beyond. Emerald Group Publishing Limited.

Rugman, A. M., Verbeke, A., y Nguyen, Q. T. (2011). Fifty years of international business theory and beyond. Management International Review, 51(6), 755-786.

Ruzzier, M., Hisrich, R. D., y Antoncic, B. (2006). SME internationalization 
research: past, present, and future. Journal of small business and enterprise development, 13(4), 476-497.

Ruzzier, M., Antoncic, B., y Hisrich, R. D. (2007). The internationalization of SMEs: developing and testing a multi-dimensional measure on Slovenian firms. Entrepreneurship and regional development, 19(2), 161-183.

Penrose, E. (1959). The Theory of the Growth of the Firm. Londres: Brasil Blackwell.

Verbeke, A., Amin Zargarzadeh, M., y Osiyevskyy, O. (2014). Internalization theory, entrepreneurshipand international new ventures. Multinational Business Review, 22(3), 246-269.

Welch, L. S., y Luostarinen, R. K. (1993). Inward-outward connections in internationalization. Journal of International Marketing, 1(1), 44-56.
Wright, R. W., y Ricks, D. A. (1994). Trends in international business research: Twenty-five years later. Journal of International Business Studies, 25(4), 687-701.

Young, S., Bell, J., y Crick, D. (200o). The resource-based perspective and small firm internationalisation: an exploratory approach. En International Business (pp. 79-101). Londres: Palgrave Macmillan.

Zahra, S. A. (1993). A conceptual model of entrepreneurship as firm behavior: A critique and extension. Entrepreneurship theory and practice, $17(4)$, 5-21.

Zahra, S. A., y George, G. (2002). International entrepreneurship: The current status of the field and future research agenda. Strategic entrepreneurship: Creating a new mindset, 255-288.

Fecha de recepción: 5 de octubre de 2019 Fecha de aceptación: 21 de noviembre de 2019 